\title{
Di-stimuli Responsive poly(N-Isopropylacrylamide- co-Diethylaminoethylmethacrylate) Copolymer: Synthesis, Characterization and Investigation of Aqueous Dispersion Properties
}

\author{
Md. Ashaduzzaman*, Md. Shahidul Islam \\ Department of Applied Chemistry \& Chemical Engineering, \\ Faculty of Engineering and Technology, University of Dhaka, Dhaka 1000, Bangladesh
}

*E-mail address: azaman01@du.ac.bd

\begin{abstract}
We report on the synthesis, characterization and aqueous dispersion properties of well-defined double hydrophilic copolymer with $\mathrm{pH}$ - and thermo-responsive segments via atom transfer radical polymerization (ATRP). Poly( $N$-isopropylacrylamide-co-Diethylaminoethylmeth-acrylate), P(NIPAAm-co-DEAEMA), was prepared by ATRP using methyl-4-bromomethyl benzoate initiator. The product was characterized by proton-nuclear magnetic resonance $\left({ }^{1} \mathrm{H}\right.$ NMR $)$ and attenuated total reflectance infrared (ATR-IR) spectroscopy. The multi-responsive switching between unimer and two types of micellar aggregates were characterized by temperature-dependent dynamic light scattering (DLS). Self-assembles into two types spherical aggregates in $1 \mathrm{mg} / \mathrm{mL}(0.0315 \mathrm{mM})$ aqueous solution, depending on solution $\mathrm{pH}$ and temperatures were widely investigated. The result shows two types of aggregate with large $(280 \mathrm{~nm})$ aggregate and variable sizes of small $(17 \mathrm{~nm}, 25 \mathrm{~nm}, 45 \mathrm{~nm})$ aggregates depending on temperature ranges from 26 to $40^{\circ} \mathrm{C}$ at $\mathrm{pH} 4$.
\end{abstract}

Keywords: Di-stimuli responsive; Co-polymer; NIPAAm; DEAEMA; Nano-particle

\section{INTRODUCTION}

Over the last few decades, stimuli-responsive polymers have attracted wide attention due to the change of their physical/chemical properties in response to environmental stimuli such as $\mathrm{pH}$, pressure, ionic strength and temperature. ${ }^{1-3}$ Stimuli-responsive double hydrophilic polymers (DHPs) have applications as drug and gene nanocarriers, sensors, smart actuators, and catalysis. ${ }^{4-16}$ Certain DHPs can supramolecularly self-assemble into more than one type of aggregates, i.e., so-called "schizophrenic" aggregation, in aqueous solution upon properly tuning external conditions.

Among the polymerization methods, controlled radical polymerizations (such as ringopening polymerization (ROP) ${ }^{17,18}$ nitroxide-mediated polymerization (NMP), ${ }^{19,20}$ atom transfer radical polymerization (ATRP), ${ }^{21-23}$, and reversible addition-fragmentation chain transfer (RAFT) polymerization, ${ }^{24,25}$ have rendered the grafting-from approach more prevailing) are used for synthesis of well defined structural block polymers. 
Thermo-responsive polymers, which undergo a reversible phase transition in response to temperature, have been extensively studied and utilised. For example, the most widely studied of thermo-responsive polymer is PNIPAAm), principally on the basis of its sharp lower critical solution temperature $(\mathrm{LCST})^{26}$; the temperature at which phase separation occurs in aqueous solution.

Chen et al. ${ }^{27}$ reported the synthesis of coil-rod DHPs with pH-responsive comb-shaped polymer brushes possessing poly(methacrylic acid) side chains as the rod segment via consecutive ATRP and investigated their application as crystallization mediators. Huang et al. $^{28}$ also reported the synthesis of multiresponsive coil-rod DHPs consisting of thermoresponsive PNIPAAm) coil segment and pH-responsive poly(2-(diethylamino)ethyl methacrylate) brush as the rod segment. In the above two examples concerning coil-rod DHBCs, the rod segments are homopolymer brushes. Most recently, Huang et al. ${ }^{29}$ also have reported the synthesis of $\mathrm{pH}$-responsive asymmetric centipede-shaped DHPs possessing poly(methacrylic acid) and short poly(ethylene oxide) (PEO) side chains via two successive ATRP processes.

This paper details the ATRP synthesis, characterization and a detailed study of the solution thermal $/ \mathrm{pH}$ properties of distimuli-responsive P(NIPAAm-co-DEAEMA) copolymer and demonstrates how the copolymer can be used to produce so-called "schizophrenic" aggregation, in aqueous solution upon properly tuning external conditions such as temperature and $\mathrm{pH}$.

\section{MATERIALS AND METHODS}

\section{1. Materials}

4-Bromomethylbenzoyl bromide (96\%, Aldrich), copper (I) bromide (99.99\%, Nacalai Tesque) and 1,1,4,7,10,10-hexamethyltriethylenetetramine (HMTETA, 97\% Aldrich) were used as received. $N$-isopropylacrylamide (NIPAAm, $98 \%$, Wako) was purified by recrystallization from $n$-hexane and dried under vacuum at $40{ }^{\circ} \mathrm{C}$ before use. 2 (Diethylamino)ethylmethacrylate (DEAEMA, $98 \%$, Aldrich) was used without purification. Isopropyl alcohol (IPA) was purchased from Wako and used as solvents. Chloroform- $\mathrm{d}_{1}$ (Acros Organics) was used for NMR measurements.

\section{2. Synthesis of P(NIPAAm-co-DEAEMA) copolymer}

An isopropanol $(12 \mathrm{~mL})$ solution of the initiator, 4-bromomethylbenzoyl bromide (BMBB, $0.07 \mathrm{~g}, 0.50 \mathrm{mmol}$ ) was purged with argon in a round-bottom flask for 15 minutes. NIPAAm monomer $(2.98 \mathrm{~g}, 25 \mathrm{mmol})$ was added and purged with argon for another 10 minutes. Stirring was carried out with a magnetic stirrer and the solution was purged continuously. The ligand, HMTETA $(70 \mathrm{mg}, 86 \mu \mathrm{L}, 1.20 \mathrm{mmol})$ and monomer, DEAEMA (5 $\mathrm{mL}, 4.64 \mathrm{~g}, 25 \mathrm{mmol}$ ) were added successively. Finally, the catalyst, $\mathrm{Cu}(\mathrm{I}) \mathrm{Br}$ (40 mg, 0.25 mmol) was then added into the flask and purging was continued for additional 10 minutes. The flask was then placed in a preheated oil bath at $60{ }^{\circ} \mathrm{C}$. Upon catalyst addition, the solution immediately became green. After $36 \mathrm{~h}$, the polymerization was stopped, air was allowed to enter the reactor and a highly viscous green polymer solution was obtained. Purification was conducted by dialyzing entirely against deionized water using a dialysis bag (Thermo Scientific, 3,500 MW cut off) below the LCST. The obtained yield was $4.9 \mathrm{~g}$ after $72 \mathrm{~h}$ freeze-drying. 


\section{3. Characterization}

\section{3. 1. Attenuated Total Reflectance Infra-red (ATR-IR) Spectroscopy}

Spectrum (4000-600 $\mathrm{cm}^{-1}$ ) was collected to determine the chemical bond of copolymer by ATR-IR spectroscopy. The instrument was a Perkin Elmer 2000, spectrum one FT-IR spectrometer with a diamond, single bounce foundation series ATR accessory and a $45^{\circ}$ angle of incidence. Each spectrum was obtained by cumulating $32 \mathrm{scans}$ at a resolution of $4 \mathrm{~cm}^{-1}$.

\section{3. 2. Proton - Nuclear Magnetic Resonance $\left({ }^{1} \mathrm{H}-\mathrm{NMR}\right)$ Spectroscopy}

${ }^{1} \mathrm{H}$ NMR spectrum was recorded on a Bruker AV300 NMR spectrometer (resonance frequency of $400 \mathrm{MHz}$ for ${ }^{1} \mathrm{H}$ ) operated in the Fourier transform mode. $\mathrm{CDCl}_{3}$ was used as the solvent.

\section{3. 3. Dynamic Light Scattering (DLS)}

The DLS measurements were conducted using an electrophoretic light scattering spectrophotometer (Otsuka Electronics Co., Ltd., Osaka, Japan) with a $90^{\circ}$ scattering angle. The light source was a $10 \mathrm{~mW}$ He-Ne laser. All the samples were prepared by filtration with a $0.45 \mu \mathrm{m}$ Millipore filter, and the samples were kept at given temperatures to reach equilibrium before the measurements. The data were collected at a heating rate of $<0.1$ ${ }^{\circ} \mathrm{C} / \mathrm{min}$ and analyzed using the Marquardt method.

\section{RESULTS AND DISCUSSION}

\section{1. Synthesis of double hydrophilic copolymer}

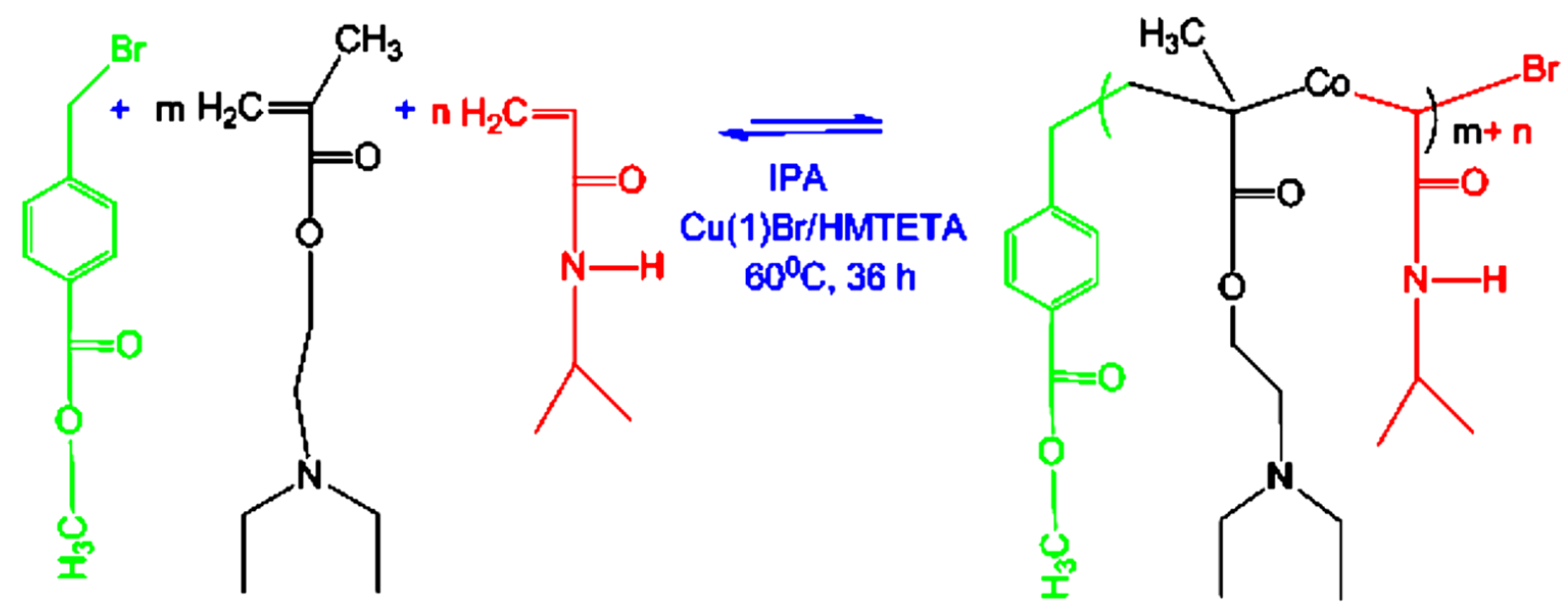

Scheme 1. Chemical reaction scheme for synthesis of P(NIPAAm-co-DEAEMA) copolymers through atom transfer radical polymerization.

Synthetic scheme employed for the preparation of P(NIPAAm-co-DEAEMA) is shown in Scheme 1, employing an ATRP technique. The isopropanol was selected as solvent for copolymerization because it is a proven very good solvent for NIPAAm homopolymerization which we used ${ }^{30}$ for tri-arm PNIPAAm synthesis in presence of HMTETA. BMBB initiator 
did not initiate NIPAAm polymerization in IPA as we tried over a range $\left(40-60{ }^{\circ} \mathrm{C}\right)$ of temperature. Since this initiator was effective for vinyl(methacrylate) monomer, an attempt was set to conduct copolymerizationusing DEAEMA monomer along with NIPAAm monomer at $60{ }^{\circ} \mathrm{C}$. In the ATR-IR spectrum (Figure 1), a strong peak at $1743 \mathrm{~cm}^{-1}$ characteristic of carbonyl functional group which attributes DEAEMA monomer unit. The peak at $1638 \mathrm{~cm}^{-1}$ represents amide moiety of NIPAAm monomer unit. These two peaks present in the spectrum prove the copolymer formation clearly.

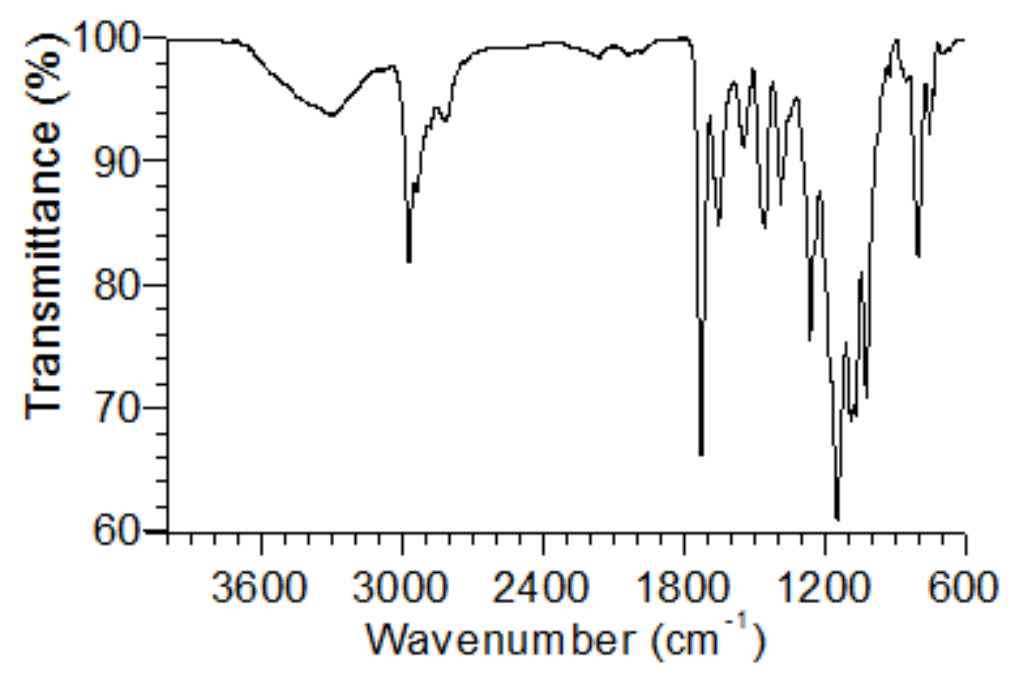

Figure 1. ATR-IR spectrum of P(NIPAAm-co-DEAEMA) copolymers.

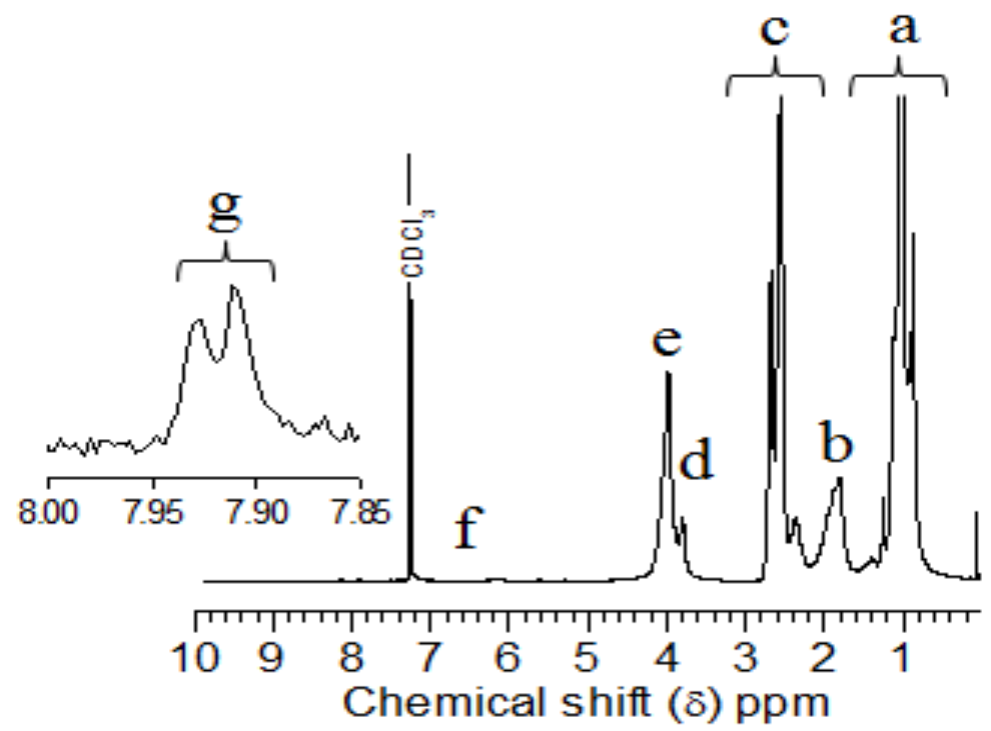

Figure 2. ${ }^{1} \mathrm{H}-\mathrm{NMR}$ spectrum of $\mathrm{P}\left(\mathrm{NIPAAm}_{85}\right.$-co-DEAEMA $\left.{ }_{140}\right)$ copolymers recorded in $\mathrm{CDCl}_{3}$ at $25^{\circ} \mathrm{C}$

A typical ${ }^{1} \mathrm{H}$ NMR spectrum of polymer is shown in Figure 2, and all signals can be well-assigned according to its chemical structure. The appearance of peaks $g(\delta=7.80-7.95$ ppm) were recorded for two phenyl protons adjacent to carbonyl group of initiator. The actual DP of the NIPAAm unit and DEAEMA unit were determined to be 85 and 140 respectively 
by ${ }^{1} \mathrm{H}$ NMR (Figure 2), by comparing integration areas of peak $\mathrm{g}$ in the range of 7.80-7.95 $\mathrm{ppm}$ to those of peaks $\mathrm{d}$ and $\mathrm{e}$ in the range of $3.80-3.95 \mathrm{ppm}$ and $3.95-4.20 \mathrm{ppm}$. The molecular weight of the polymer was estimated to be $31,700 \mathrm{gmol}^{-1}$.

\section{2. Schizophrenic" aggregation of P(NIPAAm ${ }_{85}$-co-DEAEMA $\left.{ }_{140}\right)$ copolymer}

It is well-known that NIPAAm homopolymer dissolves in cold and dilute aqueous solution but gets insoluble above $32{ }^{\circ} \mathrm{C}$ due to its lower critical solution temperature (LCST) phase behavior ${ }^{31-33}$ Below this temperature, PNIPAAm exists as a fully dissolved random coil formation. The hydrophilic parts of PNIPAAm form hydrogen bonds with water molecules. Above the LCST, as the free energy change (DG) becomes positive and entropy is increased, the hydrophobic interactions of the polymer backbone overcome the solvation forces and the random coils collapse accordingly. The polymer precipitates, leading to solution turbidity. The association of molecules leads to an increase in the viscosity of the polymer solution due to formation of bigger particles. ${ }^{34}$ Owing to the dominance of hydrophobic interactions, the collapsed polymers aggregate and appear in globular conformation. ${ }^{31}$

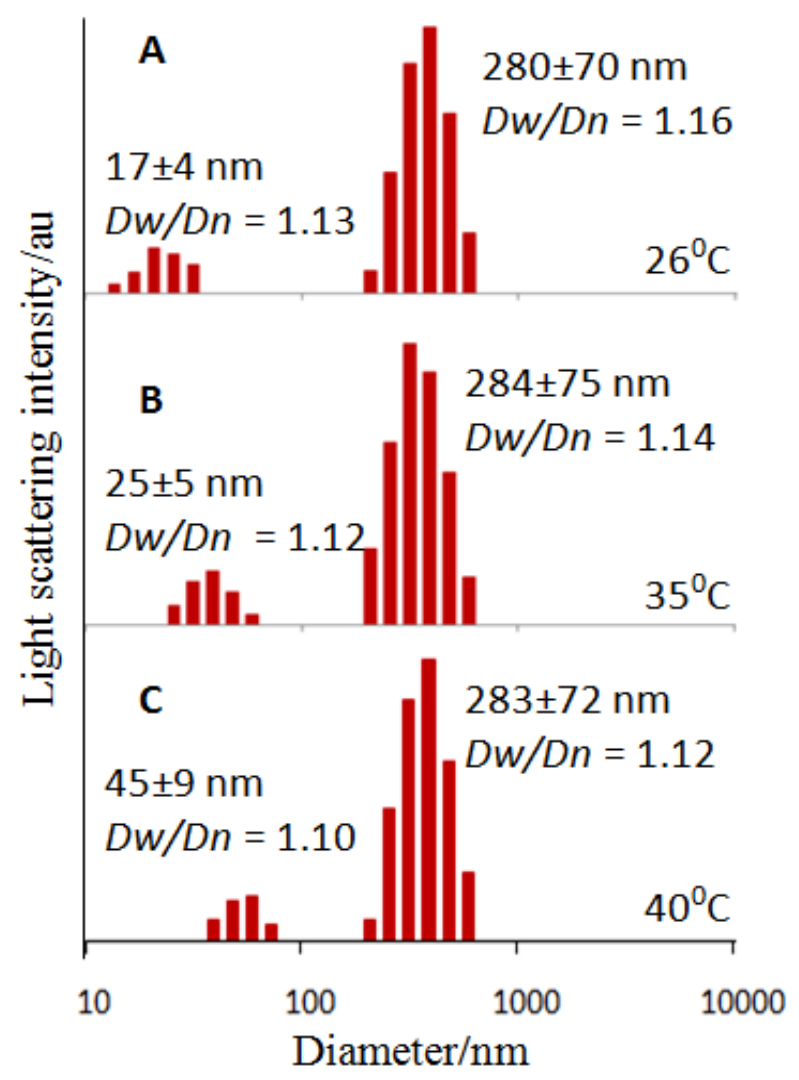

Figure 3. DLS measurement of the aqueous solution $(0.0315 \mathrm{mM})$ of P(NIPAAm85-coDEAEMA140) copolymer at $\mathrm{pH} 4$, heating rate was maintained $0.1^{\circ} \mathrm{C} / \mathrm{min}$.

On the other hand, PDEAEMA homopolymer is a weak polybase and its conjugated acid possesses a $\mathrm{pKa}$ of $\sim 7.3$. It is water-insoluble at neutral or alkaline $\mathrm{pH}$, whereas below $\mathrm{pH} 6$, it is soluble as a weak cationic polyelectrolyte due to protonation of tertiary amine residues. $^{35-39}$ Thus, we can expect that the copolymer, P(NIPAAm 85 -co-DEAEMA 140 ), 
bearing two types of PDEAEMA and PNIPAAm, should exhibit $\mathrm{pH}-$ and thermoresponsive "schizophrenic" aggregation behavior in aqueous solution. Schmidt et al. ${ }^{40}$ investigated the thermo-responsive collapse of single PNIPAAm brush in dilute aqueous solution, which is accompanied by a cylindrical brush-to-sphere transition above the phase transition temperature.

$\mathrm{P}\left(\mathrm{NIPAAm}_{85}\right.$-co-DEAEMA $_{140}$ ) is directly soluble in acidic (below $\mathrm{pH}$ 7) media at room

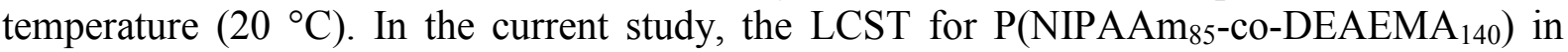
aqueous solution at a concentration of $1 \mathrm{mg} / \mathrm{mL}$ was determined to be $26^{\circ} \mathrm{C}$ by temperaturedependent optical transmittance (Figure 3). At this concentration, DLS measurement reveals too low scattering intensity to measure an average hydrodynamic radius at $20{ }^{\circ} \mathrm{C}$. With increasing temperature at $26^{\circ} \mathrm{C}$, two different sizes of aggregates $17 \mathrm{~nm}$ and $280 \mathrm{~nm}$ for the copolymer in aqueous solution was measured at $\mathrm{pH} 4$ (Figure 3). When temperature was further increased very slowly, surprisingly the bigger aggregate size did not change remarkably, but the smaller aggregate size was gradually increased with temperature. One can easily assume that the smaller aggregate had vulnerable surface to attract other smaller aggregate due to the lipophilic characteristic of the NIPAAm induced core and this aggregate sustained in aqueous solution prevailing against gravitational force. Whereas, bigger size aggregate was almost unchanged which can be demonstrated as the core aggregate was fully covered with DEAEMA further increase of size was not possible due to repulsion of other aggregate.

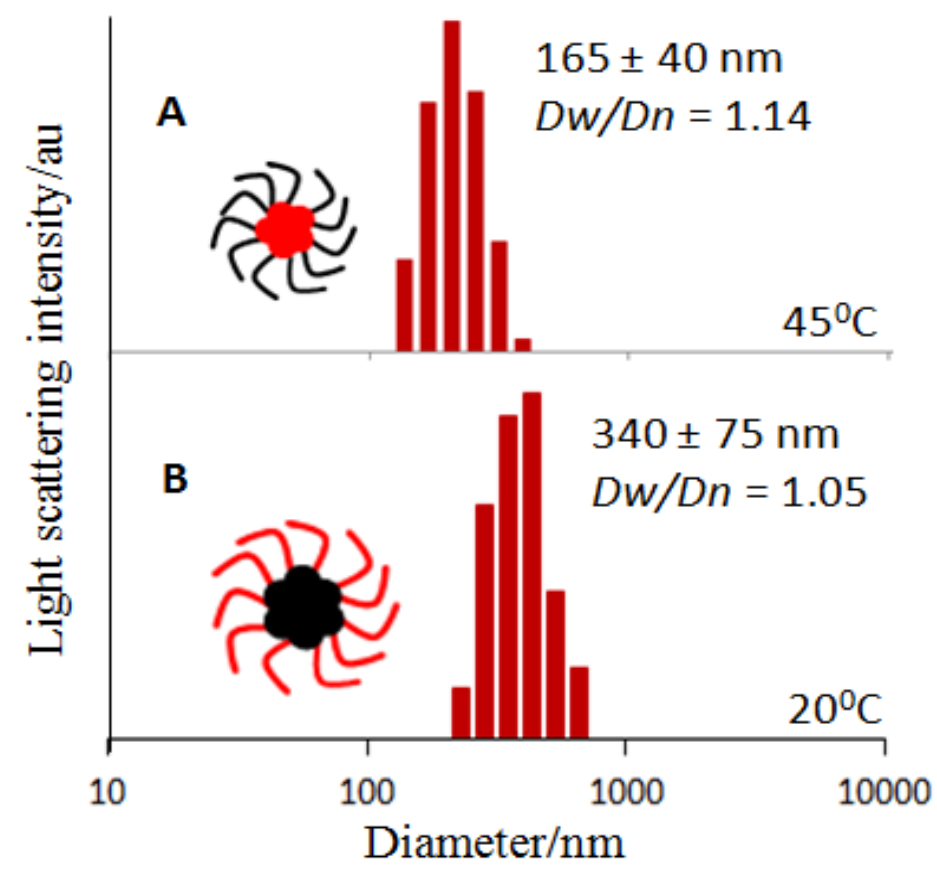

Figure 4. DLS measurement of the aqueous solution $(0.2 \mathrm{mg} / \mathrm{mL}, 0.0063 \mathrm{mM})$ of P(NIPAAm85-coDEAEMA140) copolymers (A) at $\mathrm{pH} 3$, heating rate was maintained $0.1^{\circ} \mathrm{C} / \mathrm{min}$ and (B) at $\mathrm{pH} 7$.

The di-stimuli responsive copolymer produces aggregate core and shell oppositely depending on the environment as shown in Fig. 4. When $\mathrm{pH}$ was maintained at 7, $0.2 \mathrm{mg} / \mathrm{mL}$ concentrated solution produced $\sim 340 \mathrm{~nm}$ aggregate with DEAEMA core and NIPAAm shell at $20{ }^{\circ} \mathrm{C}$ temperature. It is revealed that NIPAAm induced aggregate is smaller $(\sim 165 \mathrm{~nm})$ 
than DEAEMA induced aggregate $(\sim 340 \mathrm{~nm})$. This can be explain as the greater number of DEAEMA units present in the copolymer which have higher liphophilic tendency to aggregate and the sustainability of aggregates achieve substantially because of relatively higher hydrophilic shell monomer units. The DEAEMA induced aggregate is quite stable at below LCST of NIPAAm and above the $\mathrm{pH} \approx 7$. At $\mathrm{pH} 3$ and $20^{\circ} \mathrm{C}$, PDEAEMA units are fully protonated and remain soluble in the whole temperature range. However, heating the aqueous solution can still induce the thermal phase transition of NIPAAm units, accompanied by thermo-induced aggregation due to the double hydrophilic nature of copolymer. As revealed by temperature-dependent optical transmittance obtained for P(NIPAAm 85 -coDEAEMA $_{140}$ ) in aqueous solution at $\mathrm{pH} 3$ (Figure 4), the phase transition temperature was determined to be $\sim 45^{\circ} \mathrm{C}$. The much higher thermal phase transition temperature compared to those of NIPAAm homopolymer can be ascribed to the presence and close neighboring of highly hydrophilic protonated PDEAEMA units. Upon heating to above $45{ }^{\circ} \mathrm{C}$, the aqueous solution of polymer at $\mathrm{pH} 3$ typically exhibit a bluish tinge characteristic of colloidal dispersions, suggesting thermo-induced micellization. On the basis of chemical intuition, the formed micelles at elevated temperatures should possess a core consisting of hydrophobic PNIPAAm and a hybrid corona of well-solvated PDEAEMA sequences (Scheme 2). PDEAEMA core micelles can be fabricated via $\mathrm{pH}$ changes. Upon adjusting to $\mathrm{pH}$ higher than 7 , the initially clear solution exhibits a characteristic bluish tinge, which is just similar to that observed at $\mathrm{pH} 3$ and elevated temperatures. This suggests the formation of another type of aggregates with hydrophobic PDEAEMA as the core and well-solvated NIPAAm sequences as the corona (Scheme 2).

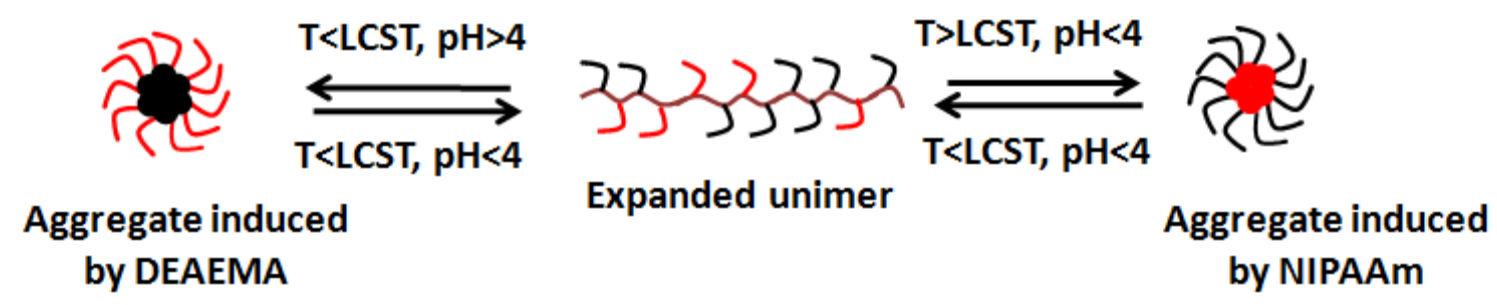

Scheme 2. Schematic presentation of aqueous dispersion phenomenon of P(NIPAAm ${ }_{85}-\mathrm{Co}^{-}$ DEAEMA $_{140}$ ) copolymers.

\section{CONCLUSION}

Well-defined double hydrophilic copolymer with di-stimuliresponsive segments, P(NIPAAm ${ }_{85}$-co-DEAEMA $\left.{ }_{140}\right)$ was synthesized via ATRP. The obtained copolymer P(NIPAAm ${ }_{85}$-co-DEAEMA $\left.{ }_{140}\right)$ showed $\mathrm{pH}$ - and thermo-responsive supramolecular aggregation behavior in aqueous solution due to the presence of dually responsive PDEAEMA and PNIPAAm segments which has been characterized via temperaturedependent optical transmittance, dynamic DLS. Moreover, the multiresponsive switching between wormlike unimers and two types of micellar aggregates can be facilely controlled by solution $\mathrm{pH}$ and temperatures, which augurs well for their potential applications as smart nanocarriers for target drug delivery and controlled release. 


\section{References}

[1] E.S. Gil, S.M. Hudson, Prog. Polym. Sci. 29 (2004) 1173.

[2] X.Z. Zhang, X.D. Xu, S.X. Cheng, R.X. Zhuo, Soft Matter 4 (2008) 385.

[3] H.K. Ju, S.Y. Kim, S.J. Kim, Y.M. Lee, J. Appl. Polym. Sci. 83 (2002) 1128.

[4] C. D. Alarcon, S. Pennadam, C. Alexander, Chem. Soc. Rev. 34 (2005) 276-285.

[5] D. Cunliffe, C. D. Alarcon, V. Peters, J. R. Smith, C. Alexander, Langmuir 19 (2003) 2888-2899.

[6] J. Hoffmann, M.; Potner, D. Kuckling, W. Fischer, J. Sens. Actuators A 77 (1999) $139-144$

[7] L. K. Ista, G. P. Lopez, J. Ind. Microbiol. Biotechnol. 20 (1998) 121-125.

[8] S. J. Kim, S. J. Park, S. M. Lee, Y. M. Lee, H. C. Kim, S. I. Kim, J. Appl. Polym. Sci. 89 (2003) 890-894.

[9] S. Y. Liu, S. P. Armes, Langmuir 19 (2003) 4432-4438.

[10] M. A. Nandkumar, M. Yamato, A. Kushida, C. Konno, M. Hirose, A. Kikuchi, T. Okano, Biomaterials 23 (2002) 1121-1130.

[11] J. Raula, J. Shan, M. Nuopponen, A. Niskanen, H. Jiang, E. I. Kauppinen, H. Tenhu, Langmuir 19 (2003) 3499-3504.

[12] G. Riess, Prog. Polym. Sci. 28 (2003) 1107-1170.

[13] J. Rodriguez-Hernandez, F. Checot, Y. Gnanou, S. Lecommandoux, Prog. Polym. Sci. 30 (2005) 691-724.

[14] H. G. Schild, Prog. Polym. Sci. 17 (1992) 163-249.

[15] D. W. Urry, Biopolymers 47 (1998) 167-178.

[16] M. Yamato, M. Utsumi, A. Kushida, C. Konno, A. Kikuchi, T. Okano, Tissue Eng. 7 (2001) 473-480.

[17] S. K. Yang, M. Weck, Macromolecules 41 (2008) 346-351.

[18] H. Zhu, G. H. Deng, Y. M. Chen, Polymer 49 (2008) 405-411.

[19] I. In, Y. H. La, S. M. Park, P. F. Nealey, P. Gopalan, Langmuir 22 (2006) 7855-7860.

[20] C. Cheng, K. Qi, E. Khoshdel, K. L. Wooley, J. Am. Chem. Soc. 128 (2006) 6808-6809.

[21] C. Feng, Z. Shen, L. N. Gu, S. Zhang, L. T. Li, G. L. Lu, X. Y. Huang, J. Polym. Sci. Part A: Polym. Chem. 46 (2008) 5638-5651.

[22] L. H. He, Zhang Y. H., Ren L. X., Chen Y. M., Wei H., Wang D. J., Macromol. Chem. Phys. 207 (2006) 684-693.

[23] S. Yamamoto, J. Pietrasik, K. Matyjaszewski, Macromolecules 40 (2007) 9348.

[24] Z. P. Cheng, X. L. Zhu, G. D. Fu, E. T. Kang, K. G. Neoh, Macromolecules 38 (2005) 7187-7192.

[25] Y. Shi, Z. F. Fu, W. T. Yang, J. Polym. Sci., Part A: Polym. Chem. 44 (2006) 2069-75. 
[26] Z. Caoa, W. Liu, P. Gao, K. Yao, H. Li, G. Wang, Polymer 46 (2005) 5268-5277.

[27] S. Y. Liu, S. P. Armes, Angew. Chem., Int. Ed. 41 (2002) 1413-1416.

[28] G. D. Poe, C. L. McCormick, J. Polym. Sci., Part A: Polym. Chem. 42 (2004) 2520-2533.

[29] J. Rodriguez-Hernandez, S. Lecommandoux, J. Am. Chem. Soc. 127 (2005) 2026-2027.

[30] M. Ashaduzzaman, S. Kai, S. Uemura, M. Kunitake, Chem. Lett. 40 (2011) 165-167.

[31] C. M. Schilli, M. F. Zhang, E. Rizzardo, S. H. Thang, Y. K. Chong, K. Edwards, G. Karlsson, A. H. E. Muller, Macromolecules 37 (2004) 7861-7866.

[32] B. S. Sumerlin, A. B. Lowe, D. B. Thomas, A. J. Convertine, M. S. Donovan, C. L. McCormick, J. Polym. Sci., Part A: Polym. Chem. 42 (2004) 1724-1734.

[33] Virtanen J., Arotcarena M., Heise B., Ishaya S., Laschewsky A., Tenhu H., Langmuir 18 (2002) 5360-5365.

[34] J. V. M. Weaver, S. P. Armes, S. Y. Liu, Macromolecules 36 (2003) 9994-9998.

[35] S. Forster, T. Plantenberg, Angew. Chem. Int. Ed. 41 (2002) 689-714.

[36] A. Ramzi, M. Prager, D. Richter, V. Efstratiadis, N. Hadjichristidis, R. N. Young, J. B. Allgaier, Macromolecules 30 (1997) 7171-7182.

[37] S. Pispas, N. Hadjichristidis, I. Potemkin, A. Khokhlov, Macromolecules 33 (2000) 1741-1746.

[38] K. Sotiriou, A. Nannou, G. Velis, S. Pispas, Macromolecules 35 (2002) 4106-4112.

[39] J. P. Yun, R. Faust, L. S. Szilagyi, S. Keki, M. Zsuga, Macromolecules 36 (2003) 1717-1723.

[40] Y. L. Cai, C. Burguiere, S. P. Armes, Chem. Commun. (2004) 802-803. 